\title{
Emerging infectious disease preparedness and response in healthcare: perspectives from COVID-19 and the role of College-Learnt Microbiology
}

\author{
${ }^{* 1}$ Tonui, J., ${ }^{2}$ Chepkutto, W., and ${ }^{3}$ Rotich, J. \\ ${ }^{1}$ Department of Biomedical Sciences-Medical Microbiology, Faculty of Medicine, Kabarak University, Nakuru, Kenya \\ ${ }^{2}$ Department of Public Health, Faculty of Medicine, Kabarak University, Nakuru, Kenya \\ ${ }^{3}$ Department of Preventive and Promotive Health, Ministry of Health, Nairobi, Kenya \\ *Correspondence to: josephat@kabarak.ac.ke
}

\begin{abstract}
:
Coronavirus disease 2019 (COVID-19) pandemic began in December 2019 in Wuhan City China where it is believed to have been transmitted to humans from an unknown animal species. The public health, social and economic impact of the pandemic world over is detrimental. Health care providers at the frontline in the fight against COVID-19 are at the greatest risk of infection and so far, many have been infected and some have already died from the disease. Thus, it is imperative that healthcare providers have adequate knowledge of infectious diseases and microbial pathogens to comprehend the scale of risk for better recognition and response. Microbiological concepts of infection prevention and control, hand hygiene and aseptic techniques are essential in slowing down the spread of the virus. COVID-19 has proven that infectious agents can emerge from any region in the world and can spread rapidly with ominous consequences to all humanity. This narrative review discusses the role of college-learnt microbiology in health care provider preparedness for emerging infectious diseases in light of the current pandemic.
\end{abstract}

Keywords: Emerging; Infections; Preparedness; Response; Microbiology; COVID-19; Training

Received Feb 18, 2021; Revised Apr 12, 2021; Accepted Apr 15, 2021

Copyright 2021 AJCEM Open Access. This article is licensed and distributed under the terms of the Creative Commons Attrition 4.0 International License <a rel="license" href="http://creativecommons.org/licenses/by/4.0/", which permits unrestricted use, distribution and reproduction in any medium, provided credit is given to the original author(s) and the source. Editor-in-Chief: Prof. S. S. Taiwo

\section{Préparation et réponse aux maladies infectieuses émergentes dans les soins de santé: perspectives du COVID-19 et le rôle de la microbiologie universitaire}

\author{
${ }^{* 1}$ Tonui, J., ${ }^{2}$ Chepkutto, W., et ${ }^{3}$ Rotich, J. \\ ${ }^{1}$ Département des sciences biomédicales-microbiologie médicale, Faculté de médecine, \\ Université Kabarak, Nakuru, Kenya \\ ${ }^{2}$ Département de santé publique, Faculté de médecine, Université de Kabarak, Nakuru, Kenya \\ ${ }^{3}$ Département de la santé préventive et promotionnelle, ministère de la Santé, Nairobi, Kenya \\ *Correspondance à: josephat@kabarak.ac.ke
}

\begin{abstract}
Abstrait:
La pandémie de maladie à coronavirus 2019 (COVID-19) a commencé en décembre 2019 dans la ville de Wuhan en Chine, où elle aurait été transmise à l'homme par une espèce animale inconnue. L'impact sanitaire, social et économique de la pandémie dans le monde est préjudiciable. Les prestataires de soins de santé en première ligne dans la lutte contre le COVID-19 sont les plus exposés au risque d'infection et jusqu'à présent, beaucoup ont été infectés et certains sont déjà morts de la maladie. Ainsi, il est impératif que les prestataires de soins de santé aient une connaissance adéquate des maladies infectieuses et des agents pathogènes microbiens pour comprendre l'ampleur du risque pour une meilleure reconnaissance et une meilleure réponse. Les concepts microbiologiques de prévention et de contrôle des infections, d'hygiène des mains et de techniques aseptiques sont essentiels pour ralentir
\end{abstract}


la propagation du virus. Le COVID-19 a prouvé que les agents infectieux peuvent émerger de n'importe quelle région du monde et se propager rapidement avec des conséquences inquiétantes pour toute l'humanité. Cet examen narratif traite du rôle de la microbiologie acquise au collège dans la préparation des fournisseurs de soins de santé aux maladies infectieuses émergentes à la lumière de la pandémie actuelle.

Mots clés: émergent; Les infections; Préparation; Réponse; Microbiologie; COVID-19; Formation

\section{Introduction:}

Emerging infectious diseases (EIDs) represent significant threats to global public health. Frequent outbreaks and epidemics continue to occur and exert immense pressure on healthcare systems all over the world (1). Over $75 \%$ of EIDs are zoonotic in nature, transmitted by direct contact with animals or their products (1). Human-to-animal interaction remains the major risk factor, and perceptions on the impact of the increasing incidence of these infections to the general public and health care workers (HCWs) influence the health system preparedness and policy interventions (2). Emerging infectious pathogens range from viruses, bacteria, fungi and protozoa (3). The emergence and global spread of antimicrobial resistant (AMR) organisms also threatens the clinical use of available antimicrobial agents for prophylaxis and management of infections (4).

COVID-19 pandemic is believed to have originated from a sea food market in Wuhan, China from an unknown animal source in December 2019 when the first case was reported. Further investigations revealed that the infection was caused by a novel strain of beta-coronavirus (CoV) that was subsequently named Severe Acute Respiratory Syndrome Coronavirus-2 (SARS-COV-2) (5). The disease quickly spread from the epicenter and on January 15, 2020, the first death was reported from Wuhan. Infection among HCWs was discovered on January 20, 2020 suggesting possible human to human transmission. The World Health Organization (WHO) declared the outbreak a Public Health Emergency of International Concern (PHEIC) on January 30, 2020 based on the imminent potential of the disease to spread internationally (6). Since the beginning of the COVID-19 pandemic, the impacts on all facets of human life including economic, political and social disruptions have been catastrophic. The pandemic has evolved tremendously and new variants of concern (VOC) have emerged in various countries, although the impact of the new strains in the human population is not yet clear. However, the virus has become more adaptive and highly virulent with marked transmissibility (7). The UK variant of SARS-CoV-2 (VOC 202012/01) for instance has been reported in over 80 countries prompting the institution of new restrictions and lockdowns to curb its spread.

At the time of concluding the manuscript for this review, the number of confirmed cases of COVID-19 globally stood at $130,459,184$ with $2,842,325$ cumulative deaths (8). Healthcare systems in various countries were ill prepared for huge influx of patients with pneumonia requiring intensive care services and ventilation (9). COVID-19 exhibits severe disease in vulnerable individuals who already have various underlying conditions that have weakened the immune system. This in part coupled with accompanying health system constraints (e. g. slow diagnostic rollout processes) have resulted in high death toll in some countries (10).

At the forefront in the fight against the pandemic are HCWs, who are mostly doctors, nurses, pharmacists, public health experts, medical laboratory personnel, medical microbiologists and other responders providing the much-needed services. It is indisputable that these professionals need a solid knowledge of the nature of infectious diseases (e. g. transmission and pathogenesis) and fundamental principles of microbiology, which are essential for diagnosis, treatment, management, epidemiology, biocontainment and infection preven tion and control (IPC) (11). Substantial contents of microbial pathogens and infectious diseases are entrenched in the respective HCW training curriculum, and for non-microbiology majors, these courses are usually taught at the preclinical level (12). HCWs need to constantly adapt and respond safely to changing infectious disease patterns and the unprecedented public health emergencies occasioned by COVID-19 pandemic and other EIDs that may arise in the future.

\section{Overview of emerging infectious diseases:}

An EID is primarily defined as one that has existed before but is rapidly increasing in incidence or geographic scope or one that has newly appeared in the population. Other definitions include drug resistant pathogens or new emerging infections which incidence has increased in the last two decades or which incidence is likely to increase in the future (3). The definition may however vary depending on classifications adopted by various experts as a result of the complex nature of these infections. Neverthe- 
less, these emerging infectious diseases remain a serious threat to global health and security. Over the years, epidemiological and geospatial information have demonstrated a steady increase in the incidence and geographic distribution of emerging pathogens. This phenomenon is thought to be driven mainly by socioeconomic, ecological and environmental factors. The peak incidence of EID was recorded in 1980 s associated with the emergence of the human immunodeficiency virus (HIV) pandemic (13). Previous attempts to understand the trends and biology of EIDs have classified viral pathogens (particularly RNA viruses) as the most significant threat due to lack of a proofreading error-correction mechanism in their genome replication cycle. As a result, they possess higher capacity to acclimatize to new hosts including humans (1). One study analyzed a database of 355 EIDs between 1940 and 2004 consisting events caused by newly emergent strains of pathogens such as multi drug resistant tuberculosis (MDR-TB) and the severe acute respiratory syndrome (SARS) coronavirus. The report showed that the majority of pathogens involved in EID events are bacterial or rickettsial (54.3\%) due to the emergence of antibacterial resistant strains. Viral pathogens or prions constituted only $25.4 \%$ of the EID events. The report further concurred with previous information regarding the incidence of EIDs due to other pathogen types which were found to be $10.7 \%$ for protozoa, $6.3 \%$ for fungi and $3.3 \%$ for helminths (13).

Over $75 \%$ of EIDs are due to zoonotic pathogens transmitted to humans from a nonhuman animal species. Wildlife sources have previously been implicated in numerous emergent EIDs, for instance the occurrence of Nipah virus in Perak, Malaysia and SARS in China, Guangdong Province (14). A number of vectors are also responsible for EID events, previous estimates reporting EIDs attributed to vectorborne diseases was put at $22.8 \%$ and $28.8 \%$ in the last decades (13). The beginning and scale of an EID is often unpredictable. Many EIDs have been identified while many remained to be discovered. The HIV/AIDS pandemic has caused great human suffering and till the present time, there has been no cure for the disease. The impacts on the healthcare system globally have been detrimental particularly in developing countries with limited resources, high population growth rate, and poverty. In 2010, the global deaths reported were 1.5 million (15). Other EIDs identified in the past years include the 2009 H1N1 influenza, enterovirus 68, hepatitis $\mathrm{C}$ and $\mathrm{E}$, Bordetella pertussis, poliovirus, and rubeola virus (16).
Several factors are responsible for the emerging and reemerging infectious diseases. Primarily, the interface between humans, animal and the environment. Human encroachment into new environments is one key factor fueling exposure to new infectious agents such the Ebola Virus Disease in 2014/2015 in West Africa (17). Chikungunya and Zika are other examples of emerging viruses that have made headlines in past few years. Chikungunya, a mosquitoborne virus which was first reported in 1952, recently mutated causing infections in several regions mainly Africa, Asia and the Americas with more than 1.25 million cases (17). In 2009, an emerging fungal pathogen Candida auris was identified in a Japanese patient. The organism exhibited extreme antifungal resistance and caused severe invasive disease among individuals with underlying co-morbidities (16).

Other factors responsible for the emergence and re-emergence include changes in human social behavior (cultural, sexual and war). Increased international travel in particular has fueled the spread of such pathogens from their source to new environments and vast regions which has been a key factor in the current COVID-19 pandemic (18). Evolution of microbial pathogens, the emergence of antibiotic resistant or antigenic microbial variants, intentional release of infectious agents (bioterrorism), lack of political will coupled with breakdown of public health systems are other key drivers (3). The classic epidemiological triad depicted in Fig 1 below explains the interaction between microorganism, host and environment, which determine disease outcome (19).

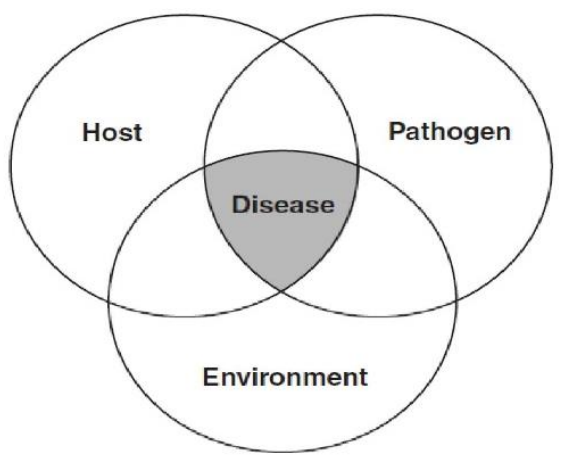

Fig 1: The classic epidemiologic triad explaining the interaction of pathogen, host and environment. Source: (19)

\section{General features of coronaviruses and SARS-COV-2}

Coronaviruses are enveloped consisting of a single stranded positive sense RNA genome with up to 32 kilobases. These viruses belong to 
the family Coronaviridae, subfamily Coronavirinae in the order Nidovirales according to the International Committee on Taxonomy of Viruses (ICTV). The viruses are named after the arrangement of spike proteins on the envelope having a crown like appearance (20). Coronaviruses were not considered highly virulent until the outbreak of severe acute respiratory syndrome (SARS) in 2002 and 2003 in Guangdong Province of China. A highly pathogenic strain Middle East respiratory syndrome coronavirus (MERS-CoV) appeared later in 2012. It was established that direct transmission of SARSCoV to humans occurred from market civets. Animal contact was consistent in all index cases and later discoveries identified SARS-CoVrelated viruses in horseshoe bats of the genus Rhinolophus, suggesting that bats are the natural reservoirs of SARS-CoV. Related strains have so far been identified in various regions globally including Africa, South East Asia and Europe (21). Similarly, the index cases of MERS$\mathrm{CoV}$ had a history of contact with dromedary camels from which direct transmission to humans originated. However further investigations identified MERS-CoVs in at least 14 species of bats from two bat families, Nycteridae and Vespertilionidae confirming that camels were intermediates (21). Patients infected by MERSCoV present with fever and cough, which progress to severe pneumonia and in some cases diarrhea is the first symptom to appear following an incubation of up to 14 days (17). Similar to the COVID-19 pandemic caused SARS-CoV-2, MERS-CoV causes severe disease in individuals with weak immunity and those with underlying conditions such as diabetes and chronic lung disease.

Severe acute respiratory syndromecoronavirus-2 (SARS-CoV-2) is a beta-coronavirus that was initially named novel coronavirus2019 (nCoV-2019). The virus is responsible for the worst global pandemic in the current civilization. The disease began in Wuhan, Hubei Province, China, around December 2019 where the first cases of flu-like disease with pneumonia of unknown aetiology were reported (22). The likely source of the infections was traced to Huanan seafood market where it was believed to have been transmitted to human from an animal species. The virus primarily targets the respiratory system leading to complication of acute respiratory distress syndrome (ARDS). Patients with COVID-19 have shown abnormal respiratory symptoms such as pneumonia, ground glass opacities and cardiac injury as well as increased leukocyte counts and pro-inflammatory cytokines which promote disease severity (10).
COVID-19 has exhibited unique features particularly with the possibility of asymptomatic individuals to transmit the virus before any symptom becomes apparent. The virus is also highly transmissible with some studies reporting an average basic reproductive number $\left(R_{0}\right)$ of 3.28 and a median of 2.79 (23). The new virus variants of concern (VOC) present a more complex scenario with the UK variant for instance exhibiting a 43-90\% (95\% CI 38-130) higher reproduction number ( 7 ). Globally, the number of cases and deaths are increasing and as of $4^{\text {th }}$ April 2021, over 4 million new cases were reported in a week, with $11 \%$ increase in mortality rate (8).

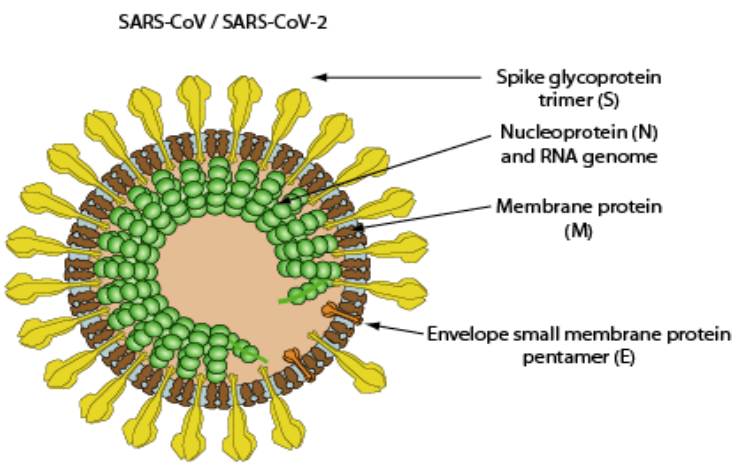

Fig 2: Schematic representation of coronavirus Source: https://viralzone.expasy.org/764?outline=all by species

\section{Consequences of emerging and re- emerging infectious diseases on healthcare workers (HCWs)}

Emerging infectious agents such as the SARS-CoV-2, MERS-CoV, Ebola virus and multidrug resistant (MDR) organisms exhibit high virulence in humans. This is mainly due to well adapted pathogen virulence factors and lack of immunity in the population. The COVID-19 pandemic has had its greatest impact on frontline healthcare workers ever witnessed in the recent years. As of March 2020, there were 3300 infections of HCWs in China and by February at least $22 \mathrm{HCWs}$ had died. In Italy, over $20 \%$ of $\mathrm{HCW}$ responding to the pandemic have acquired the infection and some had died (5). The trend is the same in other regions across the world and keeping HCWs safe is now a top priority for most governments. In part this has been attributed to shortages of personal protective equipment (PPE) such as aprons, gloves, medical masks, goggles, respirators, gowns and face shields. The shortage has been occasioned by the high-rate consumption due to huge influx of COVID-19 patients to healthcare settings increasing exposure rates for HCWs. 
The WHO estimated through modeling that 89 million medical masks and 76 million examination gloves are needed for COVID-19 response each month with international demand for goggles standing at 1.6 million per month (24, 25).

During the outbreak of Ebola Virus Disease (EVD) in 2014-2015, many HCWs were infected and the WHO reported 874 cases of EVD with 509 deaths among HCWs in West Africa (26). A systematic review including 94 articles linked to 22 outbreaks exploring the infection rates and associated risk factors for infection among HCWs during Ebola and Marburg virus outbreaks highlighted inadequate and inappropriate use of PPEs and exposure to individuals with asymptomatic Ebola and Marburg infection (27). The highest of HCWs exposed were nurses $(61 \%)$ and medical staff, hence over half of the cases were in this occupation. A similar trend has been observed in China where approximately $60 \%$ and $30 \%$ of HCWs infected were nurses and clinical personnel (28). However, with continued integration of healthcare services and patient management in healthcare delivery, there is an increased risk to other occupations which should be considered in infection prevention and control (IPC) efforts (27). With the emergence of new pathogens such as the current COVID-19 pandemic, lessons learnt from previous outbreaks should be implemented appropriately and best practices adopted to reduce the impact on health care works and the entire population.

Some of the important measures implemented in the current COVID-19 pandemic include social distancing, hand hygiene, HCW training on IPC and supply of adequate PPEs. Many countries have also implemented lockdowns to restrict movement and human interactions as well as cancellation of international travels and extensive screening at entry points. As new infections emerge, there is a greater need for sufficiently trained IPC specialists for proper response to these extraordinary events (29).

The impact of EIDS to countries and the global community are enormous as witnessed in the current COVID-19 pandemic. Therefore, every country should prepare and build the necessary capacity and infrastructure in disease surveillance, diagnostics, education, training, research, communication and strategic planning to be able to quickly recognize and respond adequately to any such events (30). Prompt and well-structured response limits the overall mortality and morbidity as well as economic implications. Newly EIDS often compete with other healthcare priorities and existing diseases hence vital resources in the healthcare system are overstretched (2). The extensive systematic review highlighted the risk factors associated with HCW infections during Ebola and Marburg outbreaks. Key among them was insufficient and inappropriate use of PPEs, lack of training in PPE and hand hygiene, multiple use of disposable PPEs and HCW refusing PPEs while caring for patients. Other important factors included inappropriate risk assessment and lack of environmental controls (27).

\section{Significance of basic microbiology training on infection control practices by healthcare providers}

Medical microbiology is a subject of medicine concerned with the study of human infectious diseases and responses to such infections. The main focus includes aetiology, pathogenesis, laboratory diagnosis, treatment, epidemiology and infection control. The subject is generally taught as a pre-requisite basic science in medical, nursing, public health, clinical medicine and other relevant paramedical courses. The subject is meant to equip learners with the knowledge of medically important microorganisms such as bacteria, viruses, protozoa, fungi and other infectious agents. The pre-clinical curricular for non-microbiology courses (nurses, doctors and public health) covers most of the infectious diseases. However, there is a continuously expanding content in this subject as new infectious agents emerge and more discoveries are made on the existing organisms (31). Some of the most important areas of concern to medical practice currently include IPC, antimicrobial resistance (AMR), EIDs, and global health, which are supposed to be taught along with the foundational microbiology course (32). In this regard, there is a greater need for adaptability in the teaching and training as well as medical microbiology content evaluation from time to time.

In recent years, there has been a surge in the frequency of healthcare associated infections which has greatly impacted patient care as well as HCWs. Healthcare associated infections (HAIs) are mainly caused by highly resistant microorganisms such as methicillin-resistant Staphylococcus aureus (MRSA) and multi-drug resistant tuberculosis (MDR-TB). The microbes colonize the hospital environment and the cycle of transmission and outbreaks can occur for an extensive period of time. The sources are either endogenous (from the patient's own flora) or exogenous (from healthcare worker's hands) (33). Prevention of HAIs is now considered part of safe and quality healthcare delivery which has 
created new demands in the health care system with significant cost implications when implementing enhanced IPC measures and the resulting longer hospital stays for infected individuals (34). Occurrence of HAIs may also have judicial consequences for responsible health facilities (35). It is estimated that $10 \%$ of hospitalized patients in the developed countries will develop a HAI while the risk in developing countries is 2-20 times more (33). EIDs such as COVID-19 (SARS-CoV-2 infection) are often noticed when HCWs have already been infected and other patients within the healthcare setting are always at risk.

In view of the emerging complexities regarding infectious diseases, it is crucial that HCWs involved in patient care possess sufficient IPC knowledge and skills in order to address these challenges in a safe manner. Basic microbiology training should empower medical students to understand the nature of infectious diseases (e. g. transmission, pathogenesis and diagnosis) and the risk level for adoption of proper IPC measures in their future clinical practice. The relevant topics include appropriate use of antibiotics, safe collection of specimen for microbial analysis, preparation of specimens for shipment and delivery, communicating microbiological results to patients and healthcare teams, and appropriate care for patients based on microbiological results and their immune status (36).

Regarding IPC, the most vital concepts include use of PPEs, hand hygiene, handling and safe disposal of sharps, aseptic techniques, clean clinical environment and decontamination (37). A number of studies have highlighted challenges in IPC compliance among nurses and clinicians. One online survey sought to evaluate the experience of student nurses in clinical placement where they were presented with a range of questions as to whether they had witnessed some lapses in IPC and the frequency of such lapses. All participants reported to have witnessed lack of compliance particularly for hand hygiene and over $75 \%$ reporting failure to clean hands between patients contact. Other lapses were witnessed in isolation precautions, poor cleaning of patient environment, changing of PPE between patients, and improper handling of sharp instruments (38). Another study that sought to evaluate the effectiveness of a special IPC training offered to nursing students before graduation reported a positive influence of the program on the students IPC knowledge, attitudes and compliance. The study used an experimental design where participants were randomly assigned to two groups with pre and post-tests which demonstrated the importance of such programs in supplementing basic curricula training (37). It has been demonstrated that nursing students have a positive attitude towards hand hygiene and IPC signifying their concern for safety and patient care. Infection prevention and control is deeply anchored in a thorough understanding of microbiological principles, particularly pathogen characteristics (transmission and pathogenesis). Therefore, IPC decisions should be based on these factors. It has been shown that HCWs often make decisions regarding IPC based on their perceived (often inaccurate) judgment of risk rather than rational application of microbiological principles (39). Therefore, failure to correctly assess the risk may compromise safety of the HCWs. Some reasons for the significantly high HCWs infections in the COVID-19 pandemic apart from the shortage of PPEs include lack of understanding of the pathogen, poor knowledge of IPC, exposure to a large number of infected patients for a long period of time, work intensity, lack of rest and pressure, lack of training on IPC for respiratory borne pathogens and lack of professional supervision and guidance on the pandemic response (28). These factors contributed to substantial HCWs exposure and infections at the onset of the outbreak.

Infectious agents are generally categorized into four biosafety levels which determine the level of containment and safety precautions needed when handling them. One factor that influences the adoption and compliance to IPC precautions has been explained through the Health Believe Model (HBM), a theory developed to explain health related behaviors. The HBM suggests that the likelihood of an individual to engage in a health related behavior is determined by their perception of four important variables; susceptibility, severity, benefit and barriers (40). Threat perception is based on two beliefs; perceived susceptibility of the individual to a certain disease and the perceived severity of the disease to the individual. Based on this concept, there is need to influence behavior change and health beliefs of HCWs to enhance the adoption of safe practices (41).

\section{Strengthening medical microbiology in academic medical training institutions}

The discovery of microorganisms in the $17^{\text {th }}$ century by Robert Hooke and Antoine van Leeuwenhoek due to their interest in microscopes laid the foundation for today's technological advancements in microbial studies (42). The world over, medical training institutions are the epitome of knowledge that can be leveraged to develop vital remedies in times of public 
health emergencies. As the pandemic rages, a number of vaccines have been developed and universities such Oxford in the UK have played a key role in this endeavor. Despite the development and rollout of COVID-19 vaccines, constraints still exist particularly the availability of enough doses for the entire population as well variants of concern (VOC) that could impact on the efficacy of the existing vaccines. Continuous research on the virology of SARS-CoV-2 is paramount for better control strategies. One significant milestone was the successful genomic sequencing of the virus which enabled further informed experiments for vaccine development (5).

Academic medical institutions are mandated to train competent healthcare personnel who can diligently serve in the community. Medical students are future HCWs and as such, sufficient training to inculcate sound knowledge of medical microbiology and IPC competency is indispensable. To facilitate compliance with set safety precautions among nursing students, it has been proposed that IPC competence should entail theoretical, practical, and decisionmaking competence (39). Based on this proposed approach, students would need to understand, analyze, synthesize, and apply the knowledge of microbiology. The decisionmaking competence would be essential for effective response in the event of an emerging infectious agent such as the current SARS-CoV2, MERS-CoV or Ebola virus which requires an in-depth understanding of microorganisms (e. g. mode transmission and portals of entry) rather than simple memorization of procedures. Another approach is the provision of additional microbiology classes and special programs focusing on important IPC concepts. Data have shown that adequate understanding of IPC and consequences of breach among HCWs improves the overall compliance (43).

To be able to recognize and respond adequately to future emerging and re-emerging infectious diseases, and to address the rising challenge of AMR, medical students should be exposed to these important concepts early in their career. The concept of "One Health" is critical considering that the majority ( $>70 \%$ ) of EIDs are zoonotic and mainly related to wild animals (44). Medical students need to have understandings of the interface between human, animal, and environmental health. This will promote future interactive multidisciplinary efforts both locally and internationally to address AMR and zoonotic diseases $(2,45)$. Medical students, nurses and clinicians should be given opportunities to participate in multidisciplinary teams involved in community and patient education on "One Health" to promote better understandings and real-life applications. This can be augmented by mentorship programs to stimulate interests in this important subject.

Antimicrobial stewardship (AMS) has been embraced as the means to address the rapidly emerging resistance to antimicrobials and to promote accountability and rational use of these medicines which are vital global resources that need to be safeguarded $(46,47)$. One of the key challenges to this initiative that has been highlighted include communication barriers between microbiology laboratories and other care units within health settings. In essence, the clinicians and the nursing staff have had challenges interpreting some of the microbiology reports while the laboratory could miss vital information in request forms mainly due to the lack of in-depth knowledge into each other's areas of expertise (48). This impediment could be addressed by equipping medical students with knowledge of various aspects of such initiatives for effective communication and implementation later in clinical practice. This will also enhance accurate patient management and timely notification of unusual infectious disease diagnosis and resistant strains.

As a public health endeavor, medical students should also be equipped with adequate knowledge of infectious disease epidemiology and sensitized on reporting of notifiable infectious agents. This will empower them to capture quality data (such as person time relationship) that can be synthesized to generate vital inferences to trace EIDs and implement timely response decisions to prevent escalation of such unusual events. Essentially this will ultimately contribute to international surveillance of EIDs and epidemic intelligence (49).

Currently, there is extensive automation of microbiology and sophisticated analytic platforms for diagnosis and research on infectious diseases. Therefore, medical students should be kept abreast with the progress so far as new instruments are introduced in routine diagnostics and patient care. Most significantly is the utility of molecular tests in diagnosis and treatment monitoring. One such platform is the GeneXpert, a cartridge based molecular assay which was developed for rapid detection of Mycobacterium tuberculosis and resistance to rifampicin (50). This technology has also been explored for the diagnosis of current COVID-19 pandemic and was granted emergency use authorization (EUA) approval by the US Food and Drug Admiration (FDA) on March 22, 2020 (51).

Innovative pedagogical approaches are 
also critical in delivery of medical microbiology, which can be adopted for concepts such as EIDs and AMS (46). There have been important developments in current education practice mainly geared towards excellence in teaching and professional development (52). One important concept is the application of a flipped classroom (FC) approach where students are first exposed to the learning materials which may be readily available online or shared by the instructor. Thereafter, time is dedicated where learners are engaged in student-centered activities that encourage active learning. This method has gained acceptance since it promotes the development of life-long skills for self-directed learning among medical students (53). Other approaches include adoption of technology and online teaching platforms which could facilitate sufficient course coverage and are equally engaging and interactive $(54,55)$. Periodic curriculum reviews are also vital to incorporate new developments in medical microbiology relevant to healthcare delivery.

\section{Conclusion:}

Emerging infectious diseases remain the greatest threat to international public health and the global economy. The current COVID-19 pandemic is causing untold human suffering with significant fear and mortality. HCWs all over the world are at the greatest risk of infection and the number infected globally is alarming while some have died. There are number of reasons for these which include among others, shortage of PPEs, inadequate training on IPC and extreme work intensity. Consequently, governments of countries have undertaken drastic measures to ensure adequate PPE supplies, training and retraining of HCWs and most importantly prioritization of HCWs in vaccine rollout.

To address these challenges now and in the future, there is need to strengthen foundational microbiology and IPC concepts during college training. Furthermore, health students should be encouraged to develop positive health beliefs to promote adoption and implementation of safe healthcare delivery practices later in their careers. To address the concerns of EIDs, sufficient infectious disease experts should be trained and international collaboration fostered. EIDs are primarily zoonotic and therefore pathogen surveillance in both domestic and wild animals should be heightened. It is now evident that infectious agents can emerge from any region across the world and as such affluent nations should invest and support countries with limited diagnostic and surveillance capacity to be able to detect and control such pathogens early. This will in future serve to avert the widespread damage as witnessed with the current COVID-19 pandemic.

\section{Funding:}

Authors received no fund for this work

\section{Acknowledgements:} given by Kabarak University

The authors are grateful for the support

\section{Conflict of interest:}

Authors declare no conflict of interest

\section{References:}

1. Gebreyes, W. A., Dupouy-camet, J., Newport, M. J., et al. The Global One Health Paradigm : Challenges and Opportunities for Tackling Infectious Diseases at the Human, Animal, and Environment Interface in Low- Resource Settings. PLoS Negl Trop Dis. $2014 ; 8$ (11): e3257.

https://doi.org/10.1371/journal.pntd.0003257

2. Meslin, F., Stöhr, K., and Heymann, D. Public health implications of emerging zoonoses Morbidity and mortality of new, Large outbreaks: the tip of the iceberg. Rev Sci Tech. 2000; 19 (1): 310-317. doi: $10.20506 /$ rst.19.1.1214

3. Morens, D. M., and Fauci, A. S. Emerging Infectious Diseases: Threats to Human Health and Global Stability. PLoS Pathog. 2013; 9 (7): e1003467 https://doi.org/10.1371/journal.ppat.1003467

4. Senok, A. C., Botta, G. A., and Soge, O. O. Emergence and spread of antimicrobial-resistant pathogens in an era of globalization. Interdiscipl Perspect Infect Dis. 2012. Article ID 286703. https://doi.org/10.1155/2012/286703

5. Yi, Y., Lagniton, P. N. P., Ye, S., Li, E., and Xu, R. H. COVID-19: What has been learned and to be learned about the novel coronavirus disease. Int J Biol Sci. 2020; 16 (10): 1753 - 1766 https://doi.org/10.7150/ijbs.45134

6. Stratton, S. J. COVID-19: Not a Simple Public Health Emergency. Prehospital and Disaster Medicine. 2020; 35 (2): 119 - 119. https://doi.org/10.1017/S1049023X2000031X

7. Davies N. G., Davies N. G., Abbott S., et al. Estimated transmissibility and impact of SARS-CoV2 lineage B.1.1.7 in England. Science. 2021; 372 (6538): eabg3055. doi:10.1126/science.abg3055.

8. World Health Organization (WHO). COVID-19 Weekly Epidemiological Update. WHO Bull. $2021 ; 34$.

9. Sohrabi, C., Alsafi, Z., Neill, N. O., Khan, M., and Kerwan, A. World Health Organization declares global emergency: A review of the 2019 novel coronavirus (COVID-19). Int J Surg. 2020; 76: 7176. doi: 10.1016/j.ijsu.2020.02.034

10. Rothan, H. A., and Byrareddy, S. N. The epidemiology and pathogenesis of coronavirus disease (COVID-19) outbreak. J Autoimmun. 2020; 109: 102433. doi: 10.1016/j.jaut.2020.102433

11. Yourassowsky E. Microbiology Research and Education: essential for the future. Future Microbiol. 2006; 1 (2): 157-160.

12. Ong, D. S. Y., Zapf, T. C., Cevik, M., Palaciosbaena, Z. R., and Bara, A. Current mentorship 
practices in the training of the next generation of clinical microbiology and infectious disease specialists : an international cross-sectional survey. Eur J Clin Microbiol Infect Dis. 2019; 38 (4): 659665.doi:10.1007/s10096-019-03509-y.

13. Jones, K. E., Patel, N. G., Levy, M. A., et al. Global trends in emerging infectious diseases. Nature. 2008;451:990-994

https://doi.org/10.1038/nature06536

14. Patz, J. A., Epstein, P. R., Burke, T. A., and Balbus, J. M. Global Climate change and emerging infectious diseases. JAMA. 1996; 275 (3): 217-223.

15. Bhutta, Z. A., Sommerfeld, J., Lassi, Z. S., Salam, R. A., and Das, J. K. Global burden, distribution, and interventions for infectious diseases of poverty. Infect Dis Poverty. 2014; 3: 21. https://doi.org/10.1186/2049-9957-3-21

16. Mcarthur, D. B. Emerging Infectious Diseases. Nurs Clin North Am. 2019: 54 (2): 297-311. https://doi.org/10.1016/j.cnur.2019.02.006

17. Beckett, G., and Kumar, A. Emerging infectious diseases: Implications for primary care. Practice Nursing. 2015; 26 (11): 542-545. https://doi.org/10.12968/pnur.2015.26.11.542

18. Contini, C., Di Nuzzo, M., Barp, N., Bonazza, A., De Giorgio, R. and Rubino, S.. The novel zoonotic COVID-19 pandemic: An expected global health concern. J Infect Dev Ctries. 2020; 14: 254 - 264. https://doi.org/10.3855/jidc. 12671

19. Chaturvedi, V., Springer, D. J., Behr, M. J., et al. Morphological and molecular characterizations of psychrophilic fungus Geomyces destructans from New York bats with white nose syndrome (WNS). PLoS One. 2010; 5 (5). https://doi.org/10.1371/journal.pone.0010783

20. Peters, A., Vetter, P., Guitart, C., Lotfinejad, N., and Pittet, D. Understanding the emerging coronavirus : what it means for health security and infection prevention. J Hosp Infect. 2020; 104 (4): 440 - 448 https://doi.org/10.1016/j.jhin.2020.02.023

21. Cui, J. Origin and evolution of pathogenic coronaviruses. Nat Rev Microbiol. 2019; 17: 181192. https://doi.org/10.1038/s41579-018-0118-9 Biswas, A., Bhattacharjee, U., Chakrabarti, A. K., Tewari, N., Banu, H., and Dutta, S. Critical Reviews in Microbiology Emergence of Novel Coronavirus and COVID-19: whether to stay or die out? Crit Rev Microbiol. 2020; 46 (2): 182-193. https://doi.org/10.1080/1040841X.2020.1739001

23. Liu, Y., Gayle, A. A., Wilder-smith, A., and Rocklöv, J. The reproductive number of COVID-19 is higher compared to SARS coronavirus. J Travel Med. 2020;27(2):taaa021.

\section{https://doi.org/10.1093/jtm/taaa021}

24. World Health Organization (WHO). Shortage of personal protective equipment endangering health workers worldwide. News release, Geneva. 2020. https://www.who.int/news/item/03-03-2020shortage-of-personal-protective-equipmentendangering-health-workers-worldwide.[cited 2021 Apr 10]

25. Park, C. Y., Kim, K., Roth, S., et al. Global Shortage of Personal Protective Equipment amid COVID-19: Supply Chains, Bottlenecks, and Policy Implications. ADB Briefs. 2019; 108: 1 - 8 https://www.adb.org/publications/shortage-ppecovid-19- supply-chains-bottlenecks-policy

26. Senga, M., Pringle, K., Ramsay, A., et al. Factors underlying Ebola virus infection among health workers, Kenema, Sierra Leone, 2014-2015. Clin Infect Dis. 2016; 63 (4): 454-459.

27. Selvaraj, S. A., Lee, K. E., Harrell, M., Ivanov, I., and Allegranzi, B. Infection Rates and Risk Factors for Infection Among Health Workers During Ebola and Marburg Virus Outbreaks: A Systematic Review. J Infect Dis. 2018; 218 (5): S679-S689. https://doi.org/10.1093/infdis/jiy435

28. Wang, J., Zhou, M., and Liu, F. Reasons for healthcare workers becoming infected with novel coronavirus disease 2019 in China. J Hosp Infect 2020;105(1):100-101

https://doi.org/10.1016/j.jhin.2020.03.002

29. Winzor G., and Patel, M. Combined infection training - should we be concerned about its impact on infection prevention and control training of microbiologists in the UK? J Hosp Infect. 2015; 91 (4): 302-305.

30. Davis J. R., and Lederberg J. Public Health Systems and Emerging Infections: Assessing the Capabilities of the Public and Private Sectors. National Academic Press, Washington DC. 2000: 128.

31. Fahnert, B. Edging into the future: education in microbiology and beyond. FEMS Microbiol Lett. 2016;363(7):fnw048

https://doi.org/10.1093/femsle/fnw048

32. Melber, D. J., Teherani, A., and Schwartz, B. S. A Comprehensive Survey of Preclinical Microbiology Curricula Among US Medical Schools. Clin Infect $\begin{array}{llll}\text { Dis. } 2016 ; & & \text { (2): } 164 & -\end{array}$ https://doi.org/10.1093/cid/ciw262

33. Damani, N. Simple measures save lives: An approach to infection control in countries with limited resources. J Hosp Infect. 2007; 65: 151154.

34. Graves, N. How costs change with infection prevention efforts. Curr Opin Infect Dis. 2014; 27 (4):390-393.

https://doi.org/10.1097/QC0.0000000000000073

35. Gastmeier, P., and Vonberg, R. Outbreaks of nosocomial infections: lessons learned and perspectives. Curr Opin Infect Dis. 2008; 21 (4): 357-361. doi: 10.1097/QCO.0b013e3283013933

36. Durrant, R. J., Doig, A. K., Buxton, R. L., and Fenn, J. P. Microbiology Education in Nursing Practice. J Microbiol Biol Educ. 2017; 18 (2): 1-8. doi: $10.1128 /$ jmbe.v18i2.1224

37. Dsc, M. A., and Rn, M. D. American Journal of Infection Control Compliance of nursing students with infection prevention precautions: Effectiveness of a teaching program. AmJ Infect Contr. 2013; 41 (4):332-336.

https://doi.org/10.1016/j.ajic.2012.03.029

38. Gould, D., and Ma, N. D. American Journal of Infection Control Student nurses ' experiences of infection prevention and control during clinical placements. Am J Infect Contr. 2013; 41 (9): 760763. https://doi.org/10.1016/j.ajic.2013.01.025

39. Cox, J. L., and Simpson, M. D. Perspectives Microbiology Education and Infection Control Competency: Offering a New Perspective. J Microbiol Biol Educ. 2018; 19 (2): 1-6.

40. Orji, R., Vassileva, J., and Mandryk, R. Towards an Effective Health Interventions Design : An Extension of the Health Belief Model. Online J Public Health Inform.2012;4(3):ojphi.v4i3.4321. doi: $10.5210 / o j p h i . v 4 i 3.4321$.

41. Cox, J. L., Simpson, M. D., Letts, W., and Cavanagh, H. M. Re-thinking microbiology/infection control education to enhance the practice-readiness of health professional students: More than just a curriculum issue. Journal of Learning Design. 2015; 8 (1): 55-67. https://doi.org/10.5204/jld.v8i1.224 42. Gest, $H$. The discovery of microorganisms revisited. ASM News. 2004;70 (6):269-274.

43. Luo, Y., He, G. P., Zhou, J. W., and Luo, Y. Factors impacting compliance with standard precautions in nursing, China. Int J Infect Dis. 2010; 14 (12): e1106-e1114.

https://doi.org/10.1016/j.ijid.2009.03.037

44. Kuiken, T., Leighton, F. A., Fouchier, R. A. M., et al. Pathogen surveillance in animals. Science. 2005; 309 (5741): 1680-1681. 
45. Ryu, S., Kim, B. I., Lim, J., Tan, C. S., and Chun, B. C. One Health Perspectives on Emerging Public Health Threats. J Prev Med Public Health. 2017; 50 (6): 411-414.

46. O'Donnell, L. A., and Guarascio, A. J. The intersection of antimicrobial stewardship and microbiology: Educating the next generation of health care professionals. FEMS Microbiol Lett. 2017; 364 (1): 1-7.

47. Nicolle, L. E. Infection prevention issues in longterm care. Curr Opin Infect Dis. $2014 ; 27$ (4): 363369.

https://doi.org/10.1097/QC0.0000000000000071

48. Skodvin B., Aase K., Brekken, A. L., Charani, E., Lindemann, P. C., and Smith, I. Addressing the key communication barriers between microbiology laboratories and clinical units: a qualitative study. J Antimicrob Chemother. 2017; 72 (9): 2666-2672

49. Brouqui, P., Disease, I., and Service, T. M. Facing highly infectious diseases: new trends and current concepts. Clin Microbiol Infect. 2009; 15 (8): 700 705

50. Kr, S., Schiller, I., Dj, H., et al. Xpert $®$ MTB / RIF assay for pulmonary tuberculosis and rifampicin resistance in adults (Review) Xpert $\circledR$ MTB/RIF assay for pulmonary tuberculosis and rifampicin resistance in adults. Cochrane Database of Systematic Reviews 2014; 1: Art. No. CD009593. https://doi.org/10.1002/14651858.CD009593

51. Jani, J. GeneXpert SARS-CoV-2 (COVID-19) vs GeneXpert MDR/RIF (TB) test. Keep moving forward !2020.

https://doi.org/10.13140/RG.2.2.36564.14728

52. Fahnert, B. Edging into the future: education in microbiology and beyond. FEMS Microbiol Lett. 2016;363(7):1-14

https://doi.org/10.1093/femsle/fnw048

53. Sait, M. S., Siddiqui, Z., and Ashraf, Y. Advances in medical education and practice: student perceptions of the flipped classroom. Adv Med Educ Pract. 2017; 8: 317-320.

54. Gubbiyappa, K. S., Barua, A., Das, B., and Baloch, $H$. Z. Exploring the Effectiveness of Flipped Classroom with Poll Everywhere. Med Educ. 2014; 48: 5 .

55. Galway, L. P., Corbett, K. K., Takaro, T. K., Tairyan, K., and Frank, E. A novel integration of online and flipped classroom instructional models in public health higher education. BMC Med Educ. 2014; 14: 181. https://doi.org/10.1186/1472-6920-14-181 